\title{
Screening and Identification of Thermophilic Glycosyl Hydrolases Producing Microorganisms
}

\author{
Pragati Awasti ${ }^{1}$ and Smriti Shrivastava ${ }^{2 *}$ \\ ${ }^{1}$ Amity Institute of Microbial Technology, Amity University, India \\ ${ }^{2}$ Amity Institute of Biotechnology, Amity University, India \\ *Corresponding author: Smriti Shrivastava, Amity Institute of Biotechnology, Amity University, Uttar Pradesh, Noida, 201313, India
}

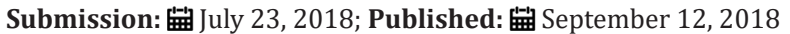

\begin{abstract}
Increasing demand of fuel and limited non-renewable fuel sources has ignited the path for alternative source of energy. Biofuel from renewable sources is proving to be the most valuable resource in the coming years. Continuous research to enhance biofuel productivity has suggested that choice of efficient raw material and process optimization for maximal bio-fuel production is needed. Present work demonstrates screening of prominent hydrolytic microorganisms and subsequent fermentation of hydrolytic products to alcohol. Five thermophilic bacterial strains were identified as Bacillus altitudinus and Bacillus stratothermophilus and could potentially produce xylanase, cellulase and amylase at $50{ }^{\circ} \mathrm{C}$, suggesting these enzymes to be thermotolerant. Crude enzyme extract showed maximal activity of about $11 \mathrm{IU} / \mathrm{ml} / \mathrm{min}$. The specific activity of extract could be considerably enhanced upon partial purification and concentration. Enzymes secreted from the selected thermophilic microorganisms are expected to be thermotolerant and thus can be used for varied industrial application.
\end{abstract}

\section{Introduction}

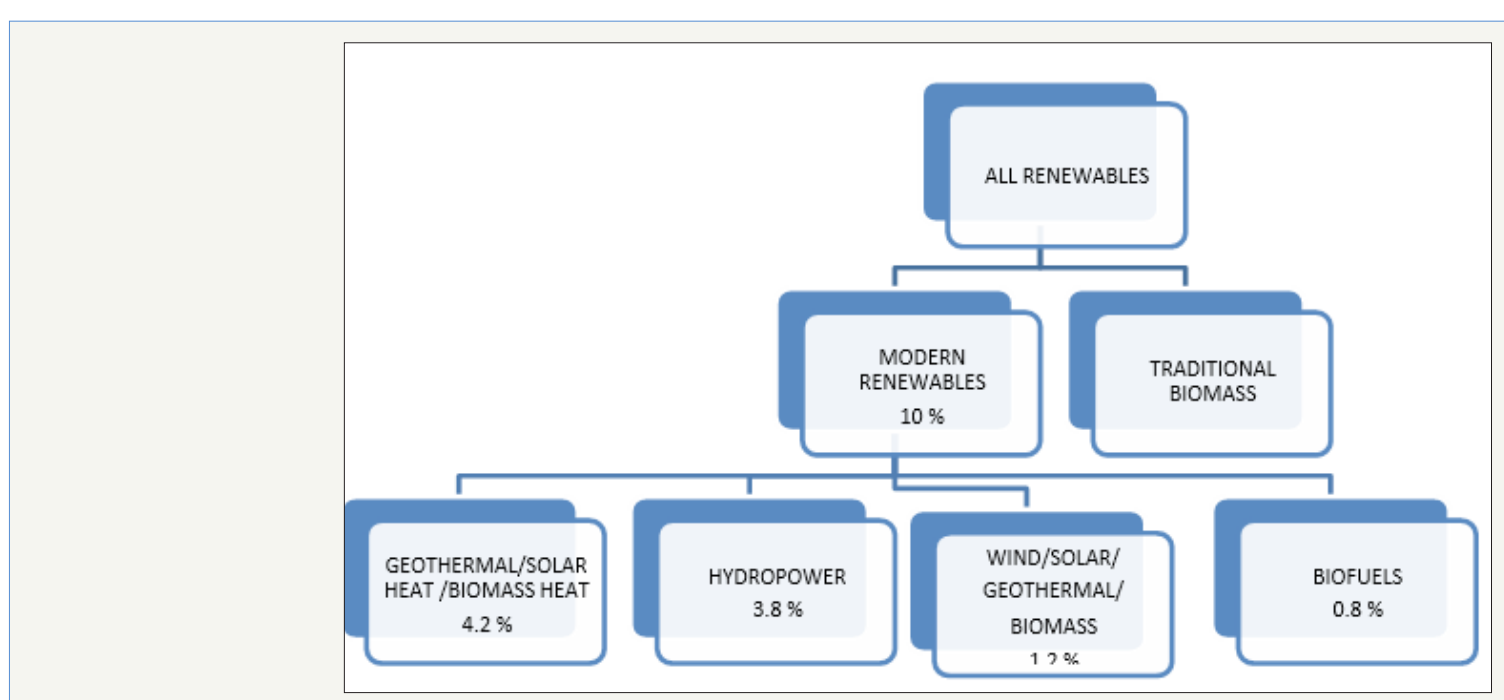

Figure 1: Distribution of all renewable energy share in different sectors (modified from Renewables, 2014, Global Status Report).

Energy is the very lifeline of human civilization. A day without electricity or fuel on an automobile brings us to the edge. Our sheer dependence on these valuable commodities, our unquenchable thirst for growth, and our imprudent negligence of its conservation has not only led to the depletion of its sources but has also brought us at the crossroads where we'll have to choose a path that has the potential to cater the needs of the future generation [1]. With the ever-growing population and industrialization, the demand for ethanol is increasing worldwide continuously. Ethanol allows fuel to burn more clearly and thus lowers greenhouse gas emissions. Blending ethanol with gasoline makes it cost effective [2]. A feasible alternative to first generation biofuel (fuel from agricultural crops) is the conversion of cellulose and hemicelluloses which is quite abundant and is renewable [3]. Major processes required for fuel 
production from agricultural waste includes saccharification and fermentation. Derivation of methyl esters and glycerol from vegetable oils (e.g. rapeseed, soybean and sunflower oils) has been considered as a promising reaction for manufacturing high quality biodiesel [4] and as compared to conventional diesel fuels, biodiesel emits almost $70 \%$ less $\mathrm{CO}_{2}$ as compared to fossil fuel. For this reason, biodiesel have been highly accepted as conventional fuel in many European nations. Renewable energy sources primarily comprise of hydropower generation, geothermal energy, solar power, wind energy and biofuels (Figure 1).

Biofuels have been classified as first, second, third and fourth generations. Here the first generation are derived from starch, sugar, vegetable oils or animal fats; second generation are obtained by processing of non-food crops and biowastes; third generation from algae and are also referred as oilgae and fourth generation via genetically engineered strain or plant varieties. Crops can also be genetically engineered which enhances $\mathrm{CO}_{2}$ consumption by plants to a level more than what is released on combustion, bringing out carbon negative cycle $[5,6]$. Ethanol has been graded as excellent fuel candidate for modern combustion engines in motors. Ethanol has an octane number 98 which is better than gasoline with an octane number of 80 [7]. Ethanol has been produced in industries by synthetic catalytic processing of petroleum products such as ethylene. For industrial application, synthetic ethanol has the maximum share as it is cheaper to produce as compared to biomass derived ethanol [8]. Bioethanol has been mainstay of beverage industry with small segment of fuel market. Five carbon and six carbon sugars are major substrates for bioethanol production. Bioethanol production includes collection and pretreatment of agricultural waste, processing of pretreated substrates, saccharification of same to produce monosaccharide sugars and its fermentation thereof. Microorganisms producing hydrolyzing and fermenting enzymes are screened and selected for developing a process with maximum output. Among fermenting organisms Pichia stipitis shows potential activity of converting pentose sugar to ethanol. Pentose sugar are present in large quantity in lignocelluloses and thus serve as major substrate for second generation bioethanol production.

\section{Materials and Methods}

\section{Isolation and screening of thermophilic extracellular xy- lanase producing bacteria}

Thermophilic bacterial strains were isolated from soil sample (collected from Delhi-NCR; India from samples containing plant wreckage material) at $50{ }^{\circ} \mathrm{C}$; they were screened for production of extracellular xylanase using RBB-xylan on nutrient agar plate (All media procured from Himedia Laboratories Pvt. Ltd., India). Selected organisms were analyzed for quantitative production of extracellular xylanases and then identified based on staining techniques and molecular identification (16S rDNA sequencing; sequencing done at GSBTM, Ahmedabad; India). Phylogenetic tree showing evolutionary relationship between identified organisms was made using multiple sequence alignment tool of CLustalW2 package (http://www.ebi.ac.uk/Tools/services/web/toolform. ebi?tool=clustalw2_phylogeny\&sequence).

\section{Optimization of process parameters for extremozyme production}

Process parameters were optimized for maximal cellulase, xylanase and amylase production, from major Indian agricultural residues (sugarcane bagasse, corn cob, wheat bran). Samples were washed, treated with $5 \% \mathrm{HCl}$ solution, dried and then grinded and sieved using mesh size $1 \mathrm{~mm}$. Two percent of these substrates were used as carbohydrate source of fermentation media containing yeast extract $(0.5 \%), \mathrm{KH}_{2} \mathrm{PO}_{4}(0.1 \%)$ and $\mathrm{NaCl}$ (0.1\%); $\mathrm{pH}$ 6.5. Saccharification process was maintained for $72 \mathrm{~h}$ at $50{ }^{\circ} \mathrm{C}$. Saccharified extracellular component were collected by centrifuging at $8000 \mathrm{rpm} / 10 \mathrm{~min} / 4^{\circ} \mathrm{C}$. Reducing sugar enzymatic assay for xylanase produced from all 5 selected strains was done using Dinitro Salicylic method [9]. Standard for xylose were prepared using dilution of xylose sugar, to which Dinitro salicylic solution was added and absorbance was read at $540 \mathrm{~nm}$ wavelength. Standard for glucose solution as prepared through similar method. Cellulase and amylase activity assay were carried out by observing intensity of hydrolysis of CMC-Cellulose (1\%) and Starch (1\%) respectively and estimating the amount of glucose in reaction sample.

\section{Results and Discussion}

\section{Screening and identification of bacterial strains}

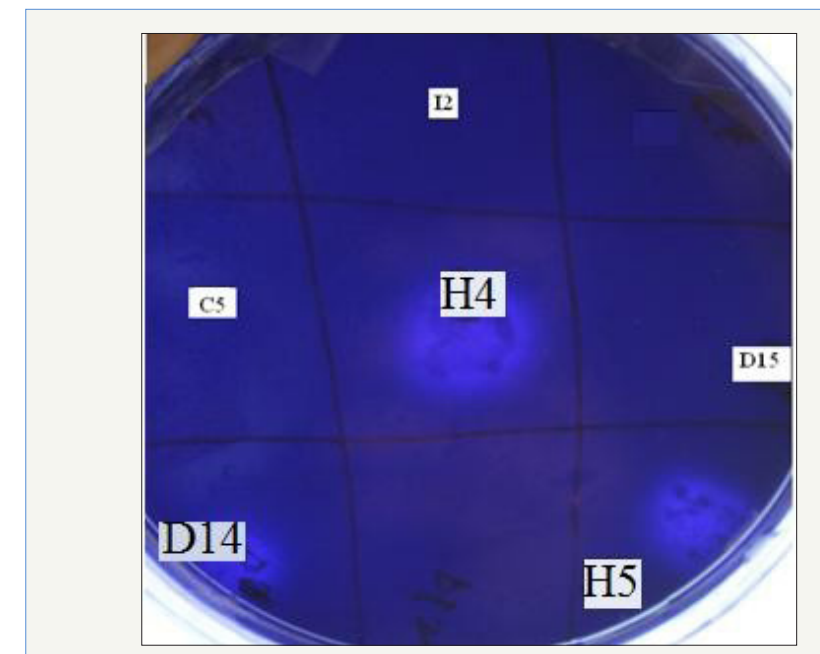

Figure 2: Screening of polysaccharide degrading thermophilic bacteria.

About 60 bacterial strains were isolated from soil samples, of which 13 thermophilic hydrolytic xylanase producing strains $\left(E_{3,} D_{14}, D_{15}, H_{5}, I_{2}, E_{5}, C_{5}, H_{4}, F_{5}, D_{5}, D_{16}, E_{2}, I_{3}\right)$ were selected for further studies. Qualitative and quantitative analysis for xylanase production resulted in selection of 5 strains (Accession number: KP119610; KP119609; KP119613; KP119611; KP119612) which could produce maximal xylanase (Figure 2). These strains were identified as Bacillus altitudinus and Bacillus stratosphericus 
based on Grams staining and molecular identification. Other

phylogenetic tree it was found that Bacillus altitudinus and Bacillus positive isolates were also identified and upon analyzing using

stratosphericus were closely linked evolutionarily (Figure 3).

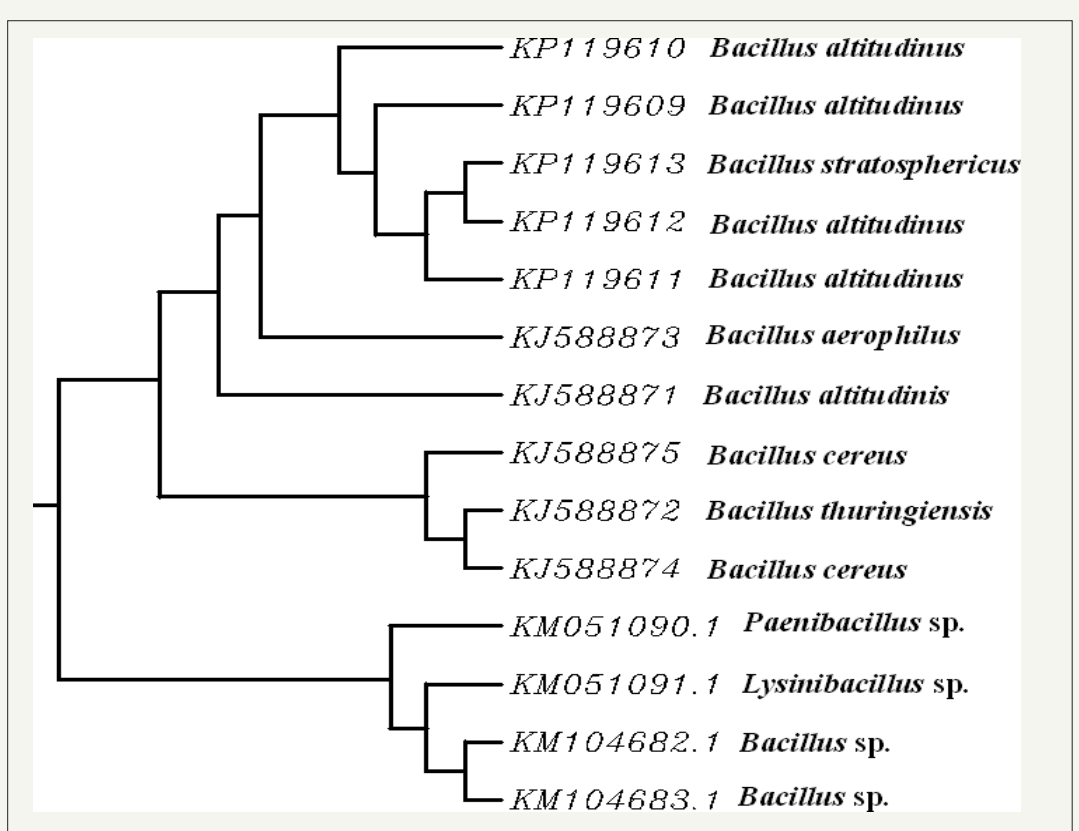

Figure 3: Phylogenetic tree for identified xylanase producing thermophilic bacteria (phylogenetic tree showing homology between various novel isolates (producing hydrolytic enzymes).

\section{Production of extracellular xylanase, cellulase and amylase}

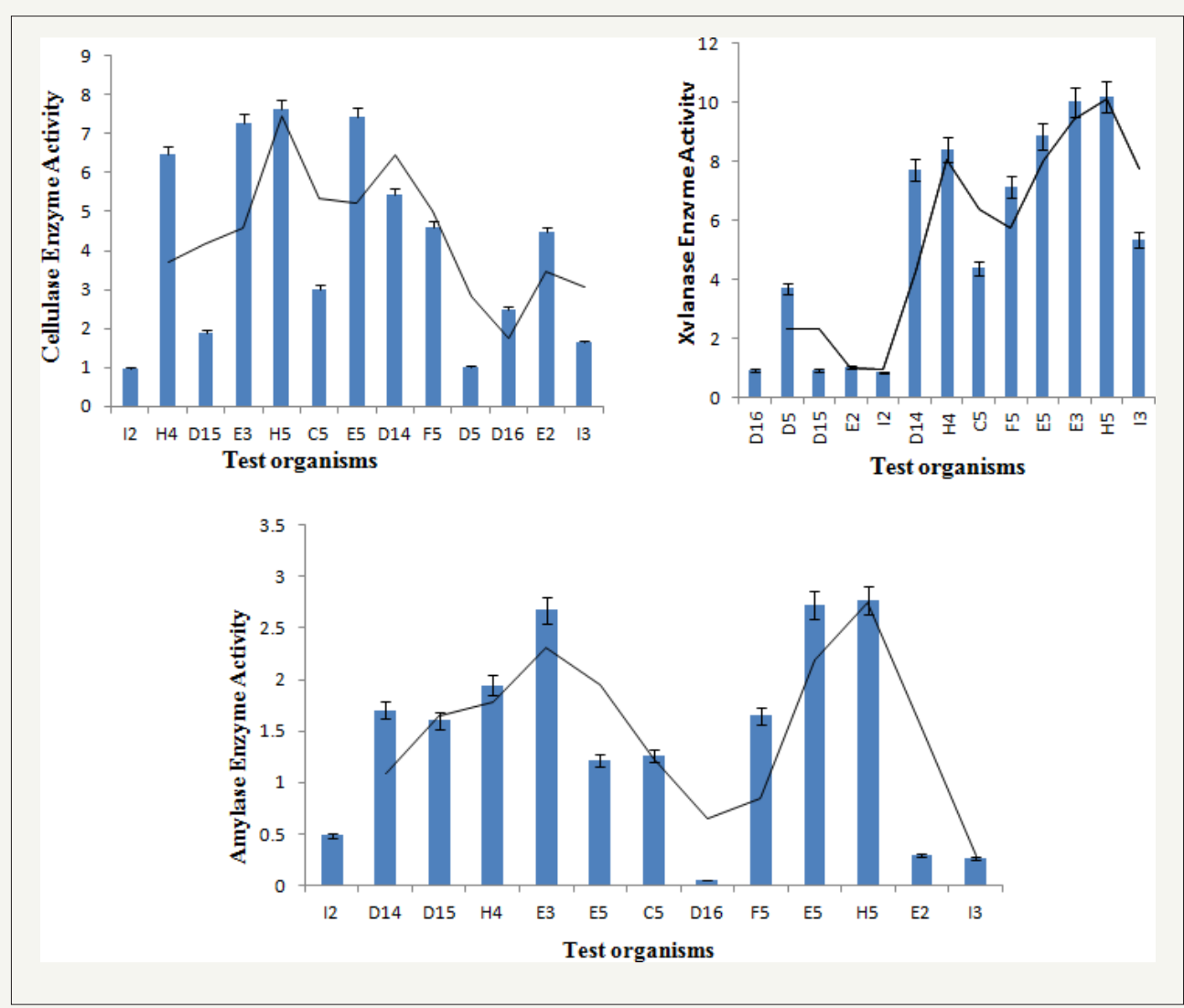

Figure 4: Comparative graph of cellulase, amylase and xylanase production by selected potential thermophilic bacterial strains. 
Among 13 thermophilic isolates 5 were efficient producers of hydrolytic enzymes. Comparative cellulase, xylanase and amylase production are reported as Figure 4. It was observed that strain $E_{3}, H_{5}$ and $E_{5}$ uniformly produced higher amount of cellulase, xylanase and amylase. These activities of these organisms were followed by those of $\mathrm{D}_{14}$ and $\mathrm{H}_{4}$. Thus, using any of these organism as saccharifying tool or using a consortium of these could lead to enhanced production of monosaccharides, available to be converted to ethanol. Based on all the above studies strain $\mathrm{E}_{5}$ was taken for further fermentation analysis and upon optimization of process parameters for extracellular enzyme production maximal activity was observed at $55^{\circ} \mathrm{C}, \mathrm{pH} 7.0$ with $1.5 \mathrm{~g}$ substrate concentration (Figure 5).

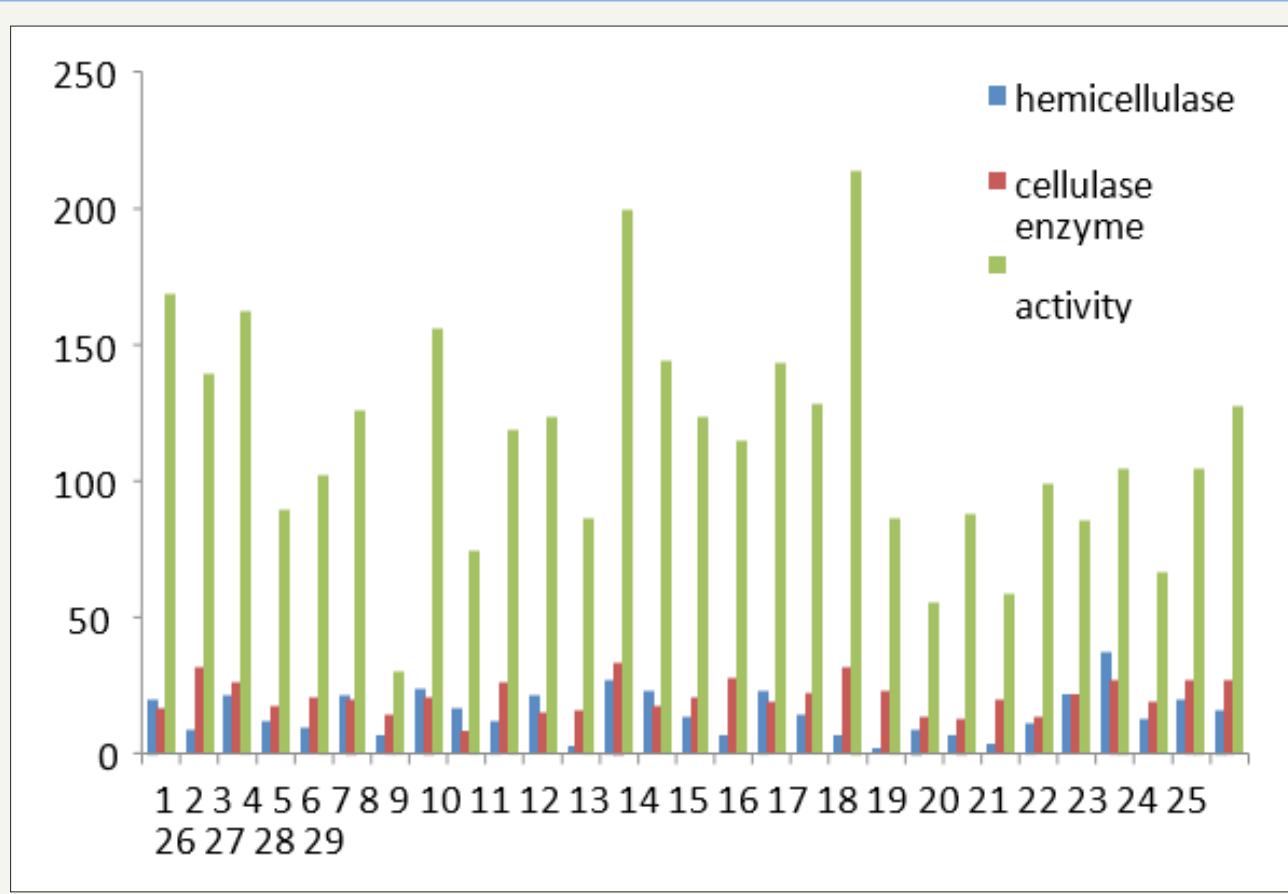

Figure 5: Optimization of physico-chemical characteristics by of extracellular enzyme production by bacterial strain $\mathrm{E}_{5}$.

\section{Conclusion}

Various potential thermophilic bacteria capable of producing thermotolerant glycosyl hydrolases have been isolated and identified. These organisms were able to produce significant number of enzymes (in crude sample) and thus can be of great industrial importance individually or in consortium. Four out of five isolates were Bacillus altitudinus and one was identified to be Bacillus stratosphericus. These are rare strains from soil samples and will further be extensively studied for their application in production of value added products. Numerous studies are ongoing for production of value added products from microbial strains [1013] and we assume that these indigenous microbial strains will as well show their potential application.

\section{Acknowledgment}

We are thankful to Science and Engineering Research Board (YSS/2012/) for providing financial support for the current research work.

\section{References}

1. Demeke MM, Dietz H, Li Y, Moreno MRF, Mutturi S, et al. (2013) Development of a D-xylose fermenting and inhibitor tolerant industrial Saccharomyces cerevisiae strain with high performance in lignocellulose hydrolysates using metabolic and evolutionary engineering. Biotechnol Biofuels 6(1): 89 .
2. Louime C, Uckelmann H (2008) Cellulosic ethanol: securing the planet future energy needs. Int J Mol Sci 9(5): 838-841.

3. Buaban B, Inoue H, Yano S, Tanapongpipat S, Ruanglek V, et al. (2010) Bioethanol production from ball milled bagasse using an on-site produced fungal enzyme cocktail and xylose-fermenting Pichia stipitis. J Biosci Bioeng 110(1): 18-25.

4. Bournay L, Casanave D, Delfort B, Hillion G, Chodorge JA (2005) New heterogeneous process for biodiesel production: A way to improve the quality and the value of the crude glycerin produced by biodiesel plants. Catalysis Today 106(1-4): 190-192.

5. Picket J, Anderson D, Bowles D, Bridggwater T, Jarvis P, et al. (2008) Sustainable biofuel, pros pests and challenges. The Royal Society, London, UK, pp. 1-90.

6. Marica PB (2009) A review of the advances in biofuel production. Journal of Agriculture and Food Chemistry 1(1): 77-84.

7. Coelho ST, Goldemberg J (2004) Alternative transportation fuels, contemporary case studies. In Encyclopedia of Energy, Elsevier 1: 67-80.

8. Biewinga EE, Van der Biji G (1996) Sustainability of energy crops (CLM234-the Netherlands) bioproduct development. Trends in Biotechnology 19: 172-177.

9. DuBois M, Gilles KA, Hamilton JK, Rebers PA, Smith F (1956) Colorimetric methods for determination of sugars and related substances. Analytical Chemistry 28(3): 350-356.

10. Ponzano BC, Perugino G, Trincone A, Mazzone M, Lauro BD, et al. (2010) Applications in biocatalysis of glycosyl hydrolases from the hyperthermophilic archaeon sulfolobus solfataricus. Biocatalyst and Biotransformation 21(4-5): 215-221. 
11. Trincone A (2018) Update on marine carbohydrate hydrolyzing enzymes: Biotechnological Applications. Molecules 23(4): pii 901.

12. Ezeilo UR, Zakaria II, Huyop F, Wahab RA (2017) Enzymatic breakdown of lignocellulosic biomass: the role of glycosyl hydrolases and lytic polysaccharide monooxygenases. Review; Agriculture and Environmental Biotechnology 31(4): 647-662.
13. Wang J, Li Y, Lu F (2018) Molecular cloning and biochemical characterization of an $\alpha$-amylase family from Aspergillus niger. Electronic Journal of Biotechnology 32: 55-62.

For possible submissions Click Here Submit Article

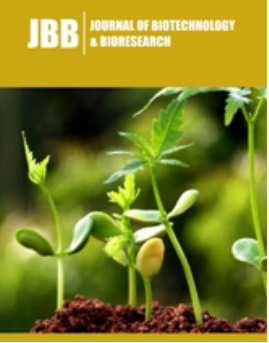

\section{Journal of Biotechnology \& Bioresearch}

\section{Benefits of Publishing with us}

- High-level peer review and editorial services

- Freely accessible online immediately upon publication

- Authors retain the copyright to their work

- Licensing it under a Creative Commons license

- Visibility through different online platforms 